03

\title{
Влияние начального давления полидисперсных пузырьковых сред на характеристики волн детонации
}

\author{
(C) А.И. Сычев \\ Институт гидродинамики им. М.А. Лаврентьева СО РАН, \\ 630090 Новосибирск, Россия \\ e-mail: sychev@hydro.nsc.ru
}

(Поступило в Редакцию 14 июня 2016 г.)

\begin{abstract}
Экспериментально исследовано влияние начального давления полидисперсных пузырьковых сред на условия инициирования, структуру, скорость распространения и давление детонационных волн. Установлено, что варьирование начального давления пузырьковой среды является эффективным способом управления параметрами волн „пузырьковой“ детонации.
\end{abstract}

DOI: 10.21883/JTF.2017.04.44308.1926

\section{Введение}

Детонация - диссипативный процесс: возможность распространения детонационных волн обеспечивается энерговыделением в среде, компенсирующим энергозатраты волны детонации на необратимое преобразование среды. „Пузырьковая“ детонация существует в средах с дискретным распределением источников химической энергии: в пузырьковых средах типа „химически неактивная жидкость-пузырьки химически активного газа“ вещества, способные к энерговыделению, находятся в газовой фазе (в пузырьках газа). Энерговыделение в пузырьковых средах (сжатие и воспламенение пузырьков газа в волне детонации) зависит от диаметра пузырьков [1]. Присутствие в системе пузырьков газа различных размеров влияет на процесс энерговыделения в среде и тем самым на характеристики волн детонации.

Полидисперсные пузырьковые среды - системы, жидкость в которых содержит смесь пузырьков газа различных размеров. Химически активные полидисперсные пузырьковые среды исследованы в работах [2-6].

При изменении начального давления химически активных пузырьковых сред с заданной объемной концентрацией газовой фазы массовая концентрация газа и, следовательно, энергосодержание системы меняются. Таким образом, начальное давление пузырьковой среды - параметр, влияющий на характеристики и на саму возможность существования волны детонации. Цель настоящей работы - изучить влияние начального давления полидисперсных пузырьковых сред на условия инициирования, структуру, скорость распространения и давление детонационных волн и установить возможность управления параметрами волн „пузырьковой“ детонации.

\section{Экспериментальная установка}

Экспериментальные исследования детонационных волн в полидисперсных пузырьковых средах проведены в вертикально расположенной ударной трубе с внутренним диаметром $40 \mathrm{~mm}$ и высотой $4.3 \mathrm{~m}$, состоящей из секций высокого и низкого давления с разрывной диафрагмой между ними [2]. Секция низкого давления заполнялась жидкостью, в которой пузырьки газа генерировались форсункой, установленной в торце ударной трубы. Высота столба пузырьковой среды с объемной концентрацией газовой фазы в диапазоне $0.5-6 \%$ составляла $3.55 \mathrm{~m}$.

Инициирование детонации в пузырьковых средах осуществляли ударными волнами. Ударную волну в пузырьковой среде генерировали сжиганием ацетиленокислородной стехиометрической газовой смеси $\left(\mathrm{C}_{2} \mathrm{H}_{2}+\right.$ $\left.2.5 \mathrm{O}_{2}\right)$ в секции высокого давления ударной трубы. Амплитуду (давление) ударных волн варьировали изменением начального давления смеси $\mathrm{C}_{2} \mathrm{H}_{2}+2.5 \mathrm{O}_{2}$.

Параметры детонационных волн (скорость, давление и длительность) определяли с помощью пьезоэлектрических датчиков давления, установленных по длине ударной трубы. Сигналы датчиков давления регистрировали осциллографами ОК-33М и С9-16. Свечение пузырьковых сред, сопровождающее процесс распространения детонационных волн, фиксировали фотоэлектронными умножителями ФЭУ-102, оптические вводы которых располагали диаметрально противоположно датчикам давления.

Изучены полидисперсные и (для сравнения) монодисперсные пузырьковые среды типа „химически неактивная жидкость-пузырьки химически активного газа" $L(\alpha)-\beta_{0} G$, где $L(\alpha)-$ жидкость (liquid), $G$ газ (gas), $\beta_{0}$ - объемная концентрация газовой фазы: $L(\alpha)$ - водно-глицериновые растворы с объемной концентрацией глицерина $\alpha=0,0.25$ и 0.5 (вязкость растворов $\mu=1.01 \cdot 10^{-3}, 2.27 \cdot 10^{-3}$ и $6.84 \cdot 10^{-3} \mathrm{~Pa} \cdot \mathrm{s}$ соответственно); $G$ - пузырьки химически активного газа (ацетилено-кислородная стехиометрическая газовая смесь $\left.\mathrm{C}_{2} \mathrm{H}_{2}+2.5 \mathrm{O}_{2}\right)$. Полидисперсные среды (ПДС) системы, жидкость в которых содержала смесь пузырьков газа диаметром $d_{1}-d_{4}\left(d_{1}=1.9 \pm 0.1, d_{2}=\right.$ $=2.5 \pm 0.1, d_{3}=3.9 \pm 0.2$ или $\left.d_{4}=5.0 \pm 0.3 \mathrm{~mm}\right)$ при примерно равном газосодержании для пузырьков газа 
различных размеров. Монодисперсные среды (МДС) системы, содержащие пузырьки газа одного заданного диаметра $d=d_{i}(i=1,2,3,4)$.

\section{Экспериментальные результаты и их обсуждение}

Инициировать детонацию в пузырьковых средах способны ударные волны с амплитудой, больше критической; при этом характеристики детонационных волн не зависят от условий инициирования и определяются параметрами среды (детонация в пузырьковых средах - это автоволновой процесс). Значения критической амплитуды инициирующей ударной волны $p_{1}^{*}$ в ПДС при начальном давлении $p$, равном атмосферному $p_{0}=0.1 \mathrm{MPa}$, возрастают при увеличении концентрации газовой фазы $\beta_{0}$ и при уменьшении вязкости жидкого компонента среды $\mu$ : $p_{1}^{*}=1.7$ и $1.7-3.4 \mathrm{MPa}$ при $\alpha=0.5$ и 0.25 соответственно $\left(0.5 \leq \beta_{0} \leq 6 \%\right)$. В МДС величина $p_{1}^{*}$ зависит от диаметра пузырьков газа: наименьшие значения $p_{1}^{*}$ наблюдаются в системах с пузырьками газа диаметром $d=d_{2}$; в исследованных МДС при атмосферном начальном давлении $p_{1}^{*}=1.7-6.0 \mathrm{MPa}$. При $\alpha=0$ самоподдерживающиеся режимы детонации в ПДС отсутствуют: при амплитудах инициирующих ударных волн до $6.0 \mathrm{MPa} \mathrm{наблюдаются} \mathrm{лишь} \mathrm{„пересжатые“}$ детонационные волны, затухающие по мере ослабевания поддерживающей инициирующей ударной волны.

Детонационные волны в ПДС при $\alpha=0.5, \beta_{0}=0.5 \%$ и начальном давлении в диапазоне $0.1-0.02 \mathrm{MPa}$ инициируются ударными волнами с амплитудами $\leq 1.7 \mathrm{MPa}$.

Волны „пузырьковой“ детонации в ПДС (как и в МДС) - это уединенные волны с пульсационным профилем давления (рис. 1). Свечение пузырьковой среды также имеет пульсационный характер. Пульсации давления и свечения являются следствием генерирования ударных волн и светового излучения пузырьками газа, воспламенившимися в детонационной волне. Стохастичность пульсаций давления и свечения обусловлена хаотичностью распределения пузырьков газа в жидкости.

Количественные характеристики детонационных волн зависят от вида и параметров пузырьковой среды. В ПДС

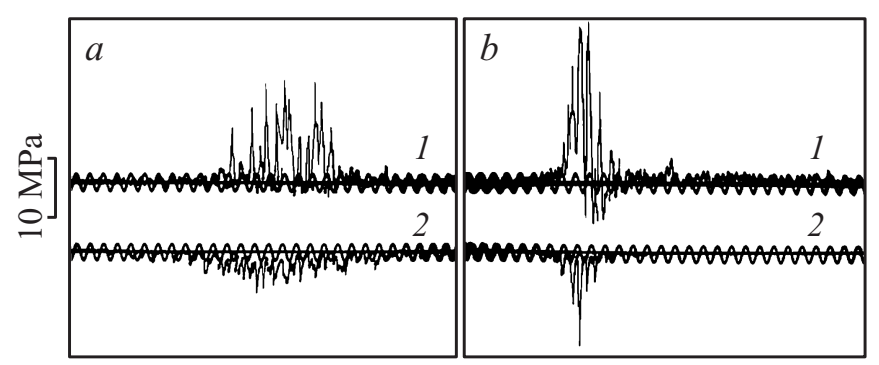

Рис. 1. Осциллограммы давления детонационных волн (1) и свечения пузырьковой среды (2). $a-$ ПДС, $\alpha=0.25$, $\beta_{0}=2 \% ; b-$ МДС, $d=d_{2}, \alpha=0.5, \beta_{0}=0.5 \% ; p=p_{0}$; период синусоиды $T=10 \mu \mathrm{s}$.

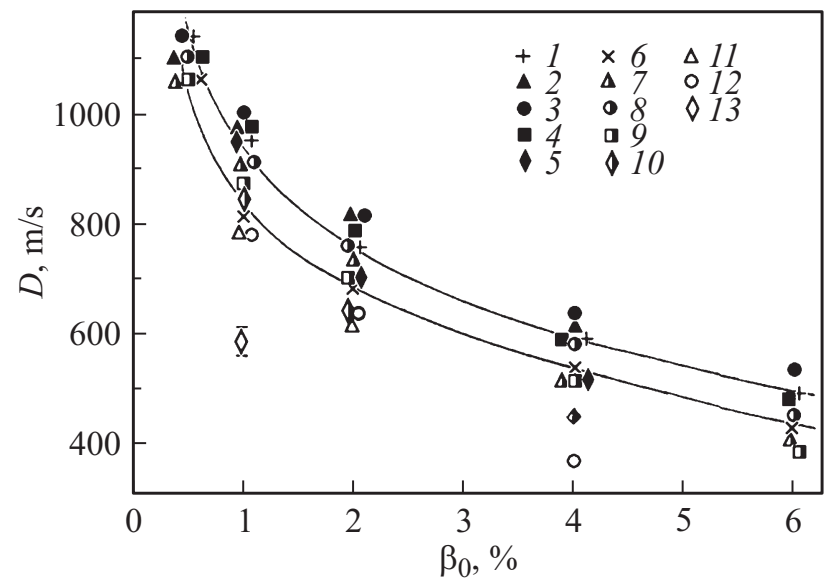

Рис. 2. Зависимости $D\left(\beta_{0}\right)$ в ПДС $(1,6)$ и МДС $(2-5,7-13)$. $\alpha=0.5(1-5), 0.25(6-10)$ и $0(11-13) ; d=d_{1}(2,7,11)$, $d_{2}(3,8,12), d_{3}(4,9)$ и $d_{4}(5,10,13) ; p=p_{0}$.

при атмосферном начальном давлении длительность волн детонации (на уровне 0.1 от максимума давления) равна примерно $120 \mu \mathrm{s}$. В МДС длительность детонационных волн определяется размером пузырьков газа и при атмосферном начальном давлении равна примерно $25,30,40$ и $50 \mu \mathrm{s}$ в системах с пузырьками газа диаметром $d=d_{1}, d_{2}, d_{3}$ и $d_{4}$ соответственно [1]; при этом длительность детонационных волн не зависит от концентрации газовой фазы и свойств жидкого компонента пузырьковых сред.

Таким образом, присутствие в ПДС пузырьков газа различного размера приводит к возрастанию длительности волн детонации по сравнению со значениями длительности детонационных волн в сопоставимых МДС в системах, содержащих пузырьки газа, диаметр которых находится в диапазоне размеров пузырьков в ПДС. Увеличение длительности позволяет волне детонации взаимодействовать с пузырьками газа различного размера.

Регистрируемая амплитуда пульсаций давления детонационных волн в МДС и ПДС при атмосферном начальном давлении, длительность которых равна $3-5 \mu \mathrm{s}$, достигает 15-40 MPa; давление в максимуме осредненного по пульсациям профиля детонационной волны составляет 6-8 МРа во всех исследованных системах [2]. За волной детонации давление близко к давлению в невозмущенной пузырьковой среде.

При понижении начального давления ПДС от атмосферного до $0.02 \mathrm{MPa}$ давление детонационных волн падает примерно в 1.5-2 раза, а длительность волн детонации остается практически неизменной.

Детонация в пузырьковых средах - это стационарный процесс. На рис. 2 приведены результаты измерения скорости распространения детонационных волн в различных ПДС при атмосферном начальном давлении (каждая точка - среднее результатов 5-10 опытов). Там же для сравнения приведены данные для МДС. Характер зависимостей $D\left(\beta_{0}\right)$ во всех исследованных пузырьковых системах является общим: с увеличением концентрации 


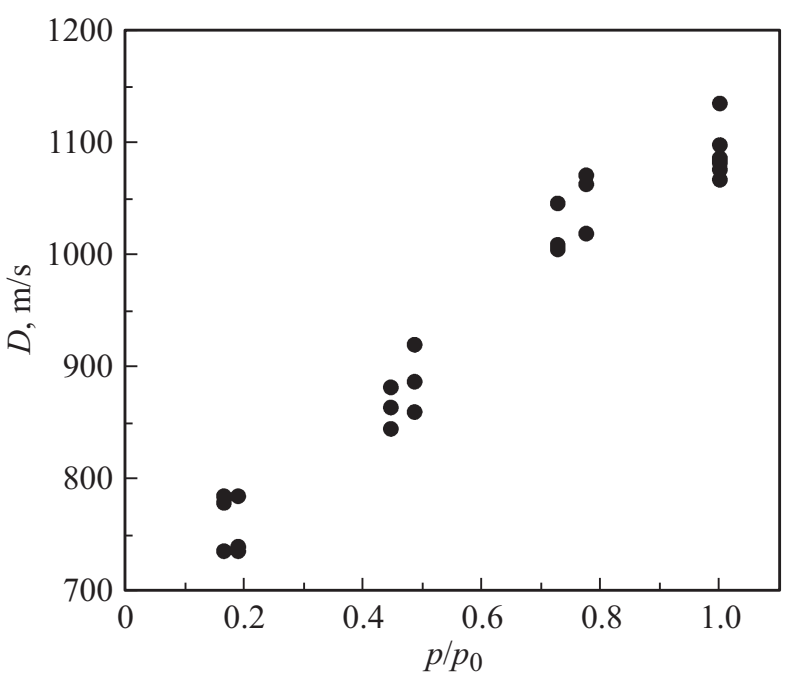

Рис. 3. Зависимости скорости детонационных волн $D\left(p / p_{0}\right)$ в ПДС. $\alpha=0.5, \beta_{0}=0.5 \%$.

газовой фазы пузырьковой среды $\beta_{0}$ скорость волн детонации $D$ снижается. C уменьшением вязкости жидкого компонента системы $\mu$ скорость детонационных волн $D$ падает.

Значения скорости распространения детонационных волн в ПДС при $\alpha=0.5$ и 0.25 находятся в диапазоне изменения скорости волн детонации в сопоставимых МДС. В ПДС при $\alpha=0$ детонация отсутствует во всем диапазоне изменения концентрации газовой фазы среды. В МДС при $\alpha=0$ волна детонации отсутствует в системах, содержащих пузырьки газа диаметром $d \leq d_{1}$ (при $\beta_{0} \geq 4 \%$ ) и $d \geq d_{4}$ (при $\beta_{0} \geq 2 \%$ ).

Существование детонационных волн возможно при условии, что энергетические потери волны компенсируются химической энергией, выделяющейся в среде при ее распространении. Если энергосодержание среды становится ниже некоторого значения или энергопотери волны детонации возрастают выше критической величины, существование детонационной волны оказывается невозможным. При фиксированной концентрации газовой фазы пузырьковой среды энергосодержание МДС и ПДС равны. Следовательно, факт существования детонационных волн в МДС и отсутствия в ПДС (при $\alpha=0$ ) указывает на то, что энергопотери волн детонации в ПДС выше, чем в МДС. Таким образом, в ПДС область существования детонации у́же, чем в сопоставимых МДС.

C уменьшением начального давления ПДС скорость распространения детонационных волн снижается (рис. 3) (скорость волн детонации измерена с помощью шести датчиков давления, расположенных на участке ударной трубы высотой $1.07 \mathrm{~m}$; при этом середина измерительного участка отстояла от поверхности пузырьковой среды на расстоянии $2.85 \mathrm{~m}$ ). В исследованном диапазоне изменения начального давления зависимости $D\left(p / p_{0}\right)$ в ПДС (как и в МДС [7]) близки к линейным (рис. 3).
Зависимость скорости и давления детонационных волн от начального давления полидисперсных пузырьковых сред обусловлена сопутствующим изменением энергосодержания системы: при понижении начального давления среды с заданной объемной концентрацией газовой фазы массовая концентрация газа и, следовательно, энергосодержание системы уменьшаются; действие этого параметра оказывается существенным: скорость распространения волн детонации падает, а давление снижается (влияние энергосодержания пузырьковых сред на параметры детонационных волн изучено в [8]).

\section{Заключение}

Экспериментально изучены детонационные волны в полидисперсных пузырьковых средах - в системах, жидкость в которых содержит пузырьки газа различных размеров. Исследовано влияние начального давления полидисперсных пузырьковых сред на условия инициирования, структуру, скорость распространения и давление детонационных волн.

Детонация в полидисперсных пузырьковых средах это самоподдерживающийся автоволновой стационарный процесс.

Инициировать детонацию в полидисперсных пузырьковых средах способны ударные волны с амплитудой, больше критической. Значения критической амплитуды инициирующей ударной волны возрастают при увеличении концентрации газовой фазы и при уменьшении вязкости жидкого компонента пузырьковой среды. В исследованных полидисперсных пузырьковых средах волны детонации инициировались ударными волнами с амплитудами до $6 \mathrm{MPa}$.

Волны „пузырьковой“ детонации в полидисперсных средах (как и в монодисперсных средах) - это уединенные волны с пульсационным профилем давления. Регистрируемая амплитуда пульсаций давления, длительность которых равна 3-5 $\mu$ s, достигает $15-40 \mathrm{MPa}$. Осредненное по пульсациям давление детонационных волн составляет 6-8 МРа во всех исследованных системах. За волной детонации давление близко к давлению в невозмущенной пузырьковой среде.

Присутствие в полидисперсных средах пузырьков газа различного размера приводит к возрастанию длительности детонационных волн по сравнению со значениями длительности волн детонации в сопоставимых монодисперсных средах.

Скорость распространения детонационных волн в полидисперсных средах, как и в монодисперсных средах, с увеличением концентрации газовой фазы и с уменьшением вязкости жидкого компонента пузырьковой среды снижается. Область существования детонационных волн в полидисперсных средах у́же области существования волн детонации в сопоставимых монодисперсных средах.

С уменьшением начального давления полидисперсных пузырьковых сред от атмосферного до $0.02 \mathrm{MPa} \mathrm{скорость}$ 
детонационных волн снижается примерно в 1.5 раза, давление падает в $1.5-2$ раза, а длительность практически не меняется. Зависимость скорости распространения и давления детонационных волн от начального давления полидисперсных сред обусловлена сопутствующим изменением энергосодержания системы.

Таким образом, варьирование начального давления полидисперсных пузырьковых сред является эффективным способом управления параметрами волн „пузырьковой“ детонации.

Работа выполнена при финансовой поддержке Российского фонда фундаментальных исследований (код проекта 13-03-01165).

\section{Список литературы}

[1] Сычев А.И. // Физика горения и взрыва. 1995. Т. 31. № 5. C. 83-91.

[2] Сычев А.И. // Физика горения и взрыва. 1997. Т. 33. № 3. С. 114-119.

[3] Сычев А.И. // Физика горения и взрыва. 1998. Т. 34. № 6. C. 71-76.

[4] Da Silva G., Dlugogorski B.Z., Kennedy E.M. // Chem. Engin. Sci. 2006. Vol. 61. N 10. P. 3186-3197.

[5] Da Silva G., Dlugogorski B.Z., Kennedy E.M. // AIChE Journal. 2006. Vol. 52. N 4. P. 1558-1565.

[6] Yakhoub H.A., Masalova I., Haldenwang R. // Chem. Engin. Commun. 2011. Vol. 198. N 2. P. 147-171.

[7] Сычев А.И. // ЖТФ. 2015. Т. 85. Вып. 4. С. 126-129.

[8] Сычев А.И. // Физика горения и взрыва. 1994. Т. 30. № 1. C. 86-91. 